\title{
Persistent photopsia: multiple evanescent white dot syndrome in a sexagenarian
}

\author{
Christine Bourke, Kirk A J Stephenson 지, Yvonne Delaney, James Morgan
}

Ophthalmology Department, Mater Misericordiae University Hospital, Dublin, Ireland

Correspondence to Dr Kirk A J Stephenson; kirkstephenson@hotmail.com

Accepted 28 September 2021

\section{DESCRIPTION}

A 67-year-old emmetropic woman presented with a 1-month history of coin-shaped flashes in her right temporal visual field with best corrected visual acuity of $6 / 6$ in each eye. She had no associated floaters, headache, viral prodrome or significant medical history.

Examination showed negative relative afferent pupillary defect, full Ishihara pseudoisochromatic colour plates, quiet anterior chambers, intraocular pressures of $15 \mathrm{~mm} \mathrm{Hg}$, no vitritis and no vitreoretinal traction, retinal tears or detachment. There were scattered yellow-orange outer retinal deposits predominantly at the right posterior pole with a distorted foveal reflex (figure 1A,B). Autofluorescence imaging (Optos, UK) showed hyperautofluorescence in a wreath-like configuration extending beyond the posterior pole (figure 1C). Fundus fluorescein angiography (Optos plc, UK) demonstrated staining in the same distribution without leakage or vasculitis (figure 1D) and indocyanine green angiography (ICGA) showed no choroidal lesions. Visual fields (Octopus, Haag-Streit, Switzerland) only showed enlargement of the right eye blind spot. Macular optical coherence tomography (OCT, Cirrus 5000, Carl Zeiss Meditec, USA) showed normal retinal lamination on B-scan; however, en face analysis revealed hyper-reflective dots at the photoreceptor inner segment/outer

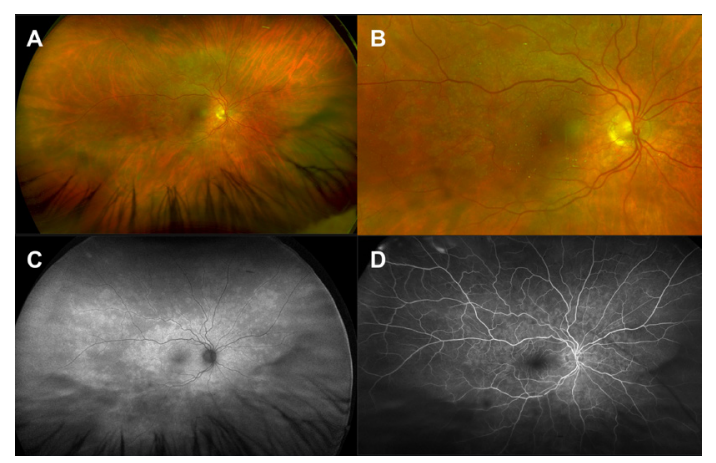

Figure 1 (A) Widefield colour photograph of the right fundus of this patient showing multiple whiteyellow subretinal dots. (B) Higher magnification colour photograph showing white-yellow dots concentrated in the macula. (C) Widefield fundus autofluorescence demonstrating wreath-like hyperautofluorescence surrounding the macula and vascular arcades. (D) Fundus fluorescein angiography of the right eye showing hyperfluorescent staining of the white dots matching the distribution seen in the autofluorescence imaging. All images were taken with the Optos 'California' camera, Optos plc, UK.

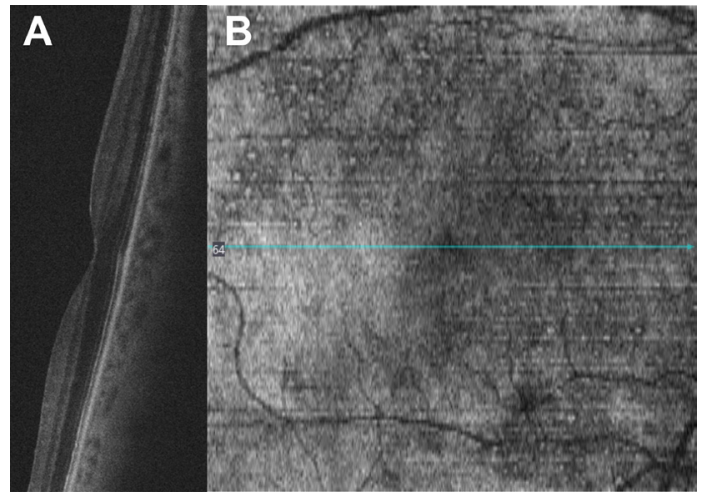

Figure 2 (A) Horizontal OCT B-scan through the fovea showing normal retinal lamination and no oedema. (B) En face infrared reflectance OCT image delineating hyperreflective foci corresponding to outer retinal white dots in figure $1 \mathrm{~A}, \mathrm{~B}$. OCT, optical coherence tomography.

segment junction (figure 2). Borrelia, tuberculosis, Toxoplasma and Treponema serology were negative and a working diagnosis of multiple evanescent white dot syndrome (MEWDS) was made. As vision was excellent, no treatment was recommended and the patient was observed closely. Symptoms had resolved at the 1-month visit including return of the blind spot to normal. Interestingly in this case, noninvasive imaging modalities (ie, autofluorescence and en face infrared reflectance imaging/OCT) were more helpful than traditional angiography in diagnosis and monitoring.

MEWDS is a rare $(0.22$ per 100000$)$, unilateral, self-limiting disease characterised by multiple discrete small white dots at the level of the outer retina, typically concentrated at the macula. ${ }^{1} 2$ Lesions typically resolve over 2-3 months. ${ }^{1}$ There is a young female predilection (mean 28 years, range 14-47 years) and a viral prodrome is reported in approximately $50 \% .^{3}{ }^{4}$ Presenting symptoms include sudden decrease in vision, paracentral scotomata and/ or temporal photopsia. ${ }^{1}$ En face infrared reflectance shows hyper-reflective outer retinal lesions corresponding to the white dots. ${ }^{56}$ ICGA may reveal peripapillary hypofluorescence and more numerous hypofluorescent lesions than expected clinically. ${ }^{7}$ Full-field electroretinogram (ERG) shows reversible photopic/scotopic a-wave attenuation, while multifocal ERG may delineate areas of normal function. ${ }^{8}$ There are no systemic manifestations. ${ }^{2}$

The aetiology of MEWDS is debated, possibly a postviral inflammatory insult to the retinal pigment epithelium/photoreceptors. ${ }^{9} \quad$ The 
diagnosis is clinical, with laboratory, electrophysiological and angiographic investigations excluding other aetiologies. ${ }^{2}$ The differential diagnosis of photopsias includes posterior vitreous detachment, optic neuritis, acute macular neuroretinopathy (AMN), acute idiopathic blind spot enlargement (AIEBS), acute zonal occult outer retinopathy and posterior uveitis (eg, sarcoid), among others. AMN (perifoveal outer nuclear layer hyper-reflectivity) and AIEBS (no discernible lesion) are rare conditions, also primarily affecting young women, resulting in central/paracentral scotomata and are considered within the MEWDS spectrum. ${ }^{3}{ }^{10}$ MEWDS is classically self-limiting ( $<3$ months) with an excellent visual prognosis without treatment, though recurrence may occur in $10 \%$.

\section{Learning points}

Multiple evanescent white dot syndrome (MEWDS) is a rare unilateral self-limiting outer retinal inflammatory disease with a young (mean 28 years) female preponderance. It is typically self-limiting with excellent visual prognosis, though can recur in $10 \%$.

- Inflammatory outer retinopathies (including MEWDS) should be included in the differential diagnosis of photopsia in the absence of vitreoretinal traction or rhegmatogenous retinal detachment.

- Diagnosis of MEWDS is clinical; however, multimodal imaging (eg, optical coherence tomography, autofluorescence, fundus fluorescein angiography, indocyanine green angiography) can be a useful diagnostic adjunct.
Contributors CB and KAJS: clinical care and manuscript drafting and revision. YD and JM: clinical care and manuscript revision.

Funding The authors have not declared a specific grant for this research from any funding agency in the public, commercial or not-for-profit sectors.

Competing interests None declared.

Patient consent for publication Consent obtained directly from patient(s).

Provenance and peer review Not commissioned; externally peer reviewed.

ORCID iD

Kirk A J Stephenson http://orcid.org/0000-0002-7462-7725

\section{REFERENCES}

1 Abu-Yaghi NE, Hartono SP, Hodge DO, et al. White dot syndromes: a 20-year study of incidence, clinical features, and outcomes. Ocul Immunol Inflamm 2011;19:426-30.

2 Jampol LM, Sieving PA, Pugh D, et al. Multiple evanescent white dot syndrome. I. clinical findings. Arch Ophthalmol 1984;102:671-4.

3 Marsiglia M, Gallego-Pinazo R, Cunha de Souza E, et al. Expanded clinical spectrum of multiple evanescent white dot syndrome with multimodal imaging. Retina 2016;36:64-74.

4 Quillen D, Davis J, et al. Perspective: the white dot syndromes. Am J Ophthalmol 2004. doi:10.1016/j.ajo.2004.01.053

5 Nguyen MHT, Witkin AJ, Reichel E, Reichel E, et al. Microstructural abnormalities in MEWDS demonstrated by ultrahigh resolution optical coherence tomography. Retina 2007:27:414-8

6 Pichi F, Srvivastava SK, Chexal S, et al. En face optical coherence tomography and optical coherence tomography angiography of multiple evanescent white dot syndrome: new insights into pathogenesis. Retina 2016;36 Suppl 1:S178-88.

7 Gross NE, Yannuzzi LA, Freund KB, et al. Multiple evanescent white dot syndrome. Arch Ophthalmol 2006;124:493-500.

8 Cheng JYC, Luu CD, Yeo IYS, et al. The outer and inner retinal function in patients with multiple evanescent white dot syndrome. Clin Exp Ophthalmol 2009;37:478-84.

9 dell'Omo R, Pavesio CE. Multiple evanescent white dot syndrome (MEWDS). Int Ophthalmol Clin 2012;52:221-8.

10 Bryan RG, Freund KB, Yannuzzi LA, et al. Multiple evanescent white dot syndrome in patients with multifocal choroiditis. Retina 2002;22:317-22.

Copyright 2021 BMJ Publishing Group. All rights reserved. For permission to reuse any of this content visit

https://www.bmj.com/company/products-services/rights-and-licensing/permissions/

BMJ Case Report Fellows may re-use this article for personal use and teaching without any further permission.

Become a Fellow of BMJ Case Reports today and you can:

- Submit as many cases as you like

- Enjoy fast sympathetic peer review and rapid publication of accepted articles

- Access all the published articles

Re-use any of the published material for personal use and teaching without further permission

Customer Service

If you have any further queries about your subscription, please contact our customer services team on +44 (0) 2071111105 or via email at support@bmj.com.

Visit casereports.bmj.com for more articles like this and to become a Fellow 